\title{
PSMB7 is associated with anthracycline resistance and is a prognostic biomarker in breast cancer
}

\author{
G Munkácsy', R Abdul-Ghani' ${ }^{2}$ Z Mihály', B Tegze', O Tchernitsa ${ }^{3}$, P Surowiak $^{3,4}$, R Schäfer ${ }^{3}$ and B Györffy,, \\ 'Joint Research Laboratory of the Hungarian Academy of Sciences and the Semmelweis University, Semmelweis University Ist Department of \\ Pediatrics, Budapest, Hungary; ${ }^{2}$ Biochemistry Department, Faculty of Medicine, Al-Quds University, East Jerusalem, Palestine; ${ }^{3}$ Laboratory of Molecular \\ Tumor Pathology, Institute of Pathology, Charité Universitätsmedizin Berlin, Berlin, Germany; ${ }^{4}$ Chair and Department of Histology and Embryology, \\ University School of Medicine, Wrocław, Poland
}

\begin{abstract}
BACKGROUND: To date individual markers have failed to correctly predict resistance against anticancer agents in breast cancer. We used gene expression patterns attributable to chemotherapy-resistant cells to detect potential new biomarkers related to anthracycline resistance. One of the genes, PSMB7, was selected for further functional studies and clinical validation.

METHODS: We contrasted the expression profiles of four pairs of different human tumour cell lines and of their counterparts resistant to doxorubicin. Observed overexpression of PSMB7 in resistant cell lines was validated by immunohistochemistry. To examine its function in chemoresistance, we silenced the gene by RNA interference (RNAi) in doxorubicin-resistant MCF-7 breast cancer cells, then cell vitality was measured after doxorubicin treatment. Microarray gene expression from GEO raw microarray samples with available progression-free survival data was downloaded, and expression of PSMB7 was used for grouping samples.

RESULTS: After doxorubicin treatment, $79.8 \pm 13.3 \%$ of resistant cells survived. Silencing of PSMB7 in resistant cells decreased survival to $31.8 \pm 6.4 \%(P>0.00$ I). A similar effect was observed after paclitaxel treatment. In I 592 microarray samples, the patients with high PSMB7 expression had a significantly shorter survival than the patients with low expression $(P<0.00 \mathrm{I})$.

CONCLUSION: Our findings suggest that high PSMB7 expression is an unfavourable prognostic marker in breast cancer.

British Journal of Cancer (2010) I 02, 36I-368. doi:I0.I038/sj.bjc.6605478 www.bjcancer.com

Published online 15 December 2009

(C) 2010 Cancer Research UK
\end{abstract}

Keywords: PSMB7; breast cancer; biomarker; doxorubicin; RNA interference; gene expression

The major cause of cancer therapy failure is either primary drug resistance or the development of secondary resistance against currently available antineoplastic agents. Many different mechanisms of drug resistance have been identified, including the overexpression of members of the family of adenosine triphosphate-binding cassette (ABC)-transporters such as P-glycoprotein $(A B C B 1)$, the multidrug resistance-associated proteins MRP1 and MRP2 and the mitoxantrone resistance protein/breast cancer resistance protein (Gottesman et al, 2002). Drug resistance is also mediated by defects in intrinsic cellular safeguard mechanisms capable of activating apoptosis. The loss of programmed cell death induced by antitumour drugs can be achieved through disruption of regulators of DNA damage signalling, such as $p 53$ and $b c l-2$. Moreover, alterations in cell cycle checkpoints, repair of damaged cellular targets and various additional more or less wellcharacterised mechanisms can contribute to the resistance.

The anthracycline antibiotic doxorubicin (adriamycin) is widely used for treatment of breast, ovarian, bronchogenic and gastric solid tumours, lymphomas and leukaemias (Martin et al, 2003).

*Correspondence: Dr B Györffy, Semmelweis University Ist Department of Pediatrics, Bokay u. 53-54, H- 083 Budapest, Hungary;

E-mail: zsalab2@yahoo.com

Received 4 August 2009; revised 6 November 2009; accepted II November 2009; published online 15 December 2009
Triple negative (ER-, PR-, HER2-) breast patients receive anthracycline-based chemotherapeutic agents in monotherapy or in combination protocols. Although a number of different mechanisms have been proposed for the cytotoxic effect of anthracyclines, the primary mechanism of drug action is likely to be the inhibition of DNA biosynthesis through topoisomerase II binding and consequently conferring an S/G2 cell cycle arrest (Gewirtz, 1999). As a topoisomerase inhibitor, it potentially induces apoptosis in normal cells as well (Sabourin and Osheroff, 2000).

In several reports, authors applied DNA array technologies to find genes correlated with doxorubicin resistance (Ayers et al, 2004; Kang et al, 2004; Folgueira et al, 2005; Gianni et al, 2005; Cleator et al, 2006; Gyorffy et al, 2006; Hess et al, 2006). In our earlier study, we used gene expression patterns of closely related chemotherapy-resistant and -sensitive parental cancer cell lines to identify discriminatory genes associated with drug resistance. The use of a set of different cell lines for the identification of discriminating genes allows a tissue-independent application for predicting therapy response. We applied our model to predict sensitivity in a set of 44 breast cancer samples. The patient group characterised by the gene expression profile similar to that of drug-sensitive cell lines exhibited over $50 \%$ longer survival than the group exhibiting the profile characteristic of resistant cells (Gyorffy et al, 2005). Overall, in these gene expression signatures, a considerable number of genes were associated with doxorubicin 
resistance. However, it is desirable to discriminate markers associated with treatment response and markers responsible for resistance.

The proteasome is a multicatalytic proteinase complex with a highly ordered ring-shaped $20 \mathrm{~S}$ core structure. The core structure is composed of 4 rings of 28 non-identical subunits; 2 rings are composed of $7 \alpha$ subunits and 2 rings are composed of $7 \beta$ subunits. Proteasomes are distributed throughout eukaryotic cells at a high concentration and cleave damaged and needless peptides in an ATP/ubiquitin-dependent process in a non-lysosomal pathway. Proteasome inhibitors are drugs blocking the action of cellular complexes that break down proteins. They have an antitumour activity in cell culture, and induce apoptosis by disturbing regulation of cell cycle proteins (Adams et al, 1999). Bortezomib was the first proteasome inhibitor, which is already used in clinics as a chemotherapy agent (Kane et al, 2006). Bortezomib effectively eradicates myelome multiplex by activating the stress apoptosis signal of endoplasmic reticulum (Schewe and guirre-Ghiso, 2009). So far, several studies examined its effect on proteasomes in different circumstances (Ludwig et al, 2005; Montagut et al, 2005; Montagut et al, 2006; Sterz et al, 2008). Proteasome inhibitors might also increase chemosensitivity. Cotreatment of doxorubicin and bortezomib can conversely increase the efficiency of each other (Ciolli et al, 2008). However, to date the direct association with doxorubicin resistance as well as the potential prognostic or predictive value of selected proteasome subunits has not been investigated.

In this study, our intention was to identify gene expression signatures obtained from resistant cells in long-term culture, untreated sensitive parental cells and parental cells after short-term drug administration. On the basis of relevance in clinical samples, we selected one proteasome subunit, the proteasome unit $\beta$-type 7 (PSMB7) for further examination using RNA interference (RNAi) to validate its function in doxorubicin resistance. Our aim was also to identify effects of paclitaxel crossresistance on the resistant cell line. Finally, microarray data from 1592 patients were used to examine the clinical relevance of PSMB7.

\section{MATERIALS AND METHODS}

\section{Cell lines}

The doxorubicin/daunorubicin-resistant derivatives of human gastric carcinoma cell line EPG85-257P, pancreatic carcinoma cell line EPP85-181P, colon carcinoma cell line HT-29 and breast cancer cell line MCF-7 were established in our laboratory as described earlier (Lage and Dietel, 2002). Cells were cultured in Leibovitz L-15 medium (Sigma-Aldrich, Budapest, Hungary) supplemented with $10 \%$ foetal calf serum (Life Sciences, Grand Island, NY, USA), $1 \mathrm{~mm}$ L-glutamine, $80 \mathrm{IE} / 1$ insulin, $2.5 \mathrm{mgl}^{-1}$ transferrin, $1 \mathrm{gl}^{-1}$ glucose, $1.1 \mathrm{gl}^{-1} \mathrm{NaHCO}_{3}, 1 \%$ minimal essential vitamins and $20000 \mathrm{kIEl}^{-1}$ trasylol in a humified atmosphere containing $5 \% \mathrm{CO}_{2}$ at $37^{\circ} \mathrm{C}$. Culture media of resistant cell lines were supplemented with daunorubicin for HT-29 $\left(0.125 \mu \mathrm{g} \mathrm{ml}^{-1}\right)$, EPP85-181 $\left(2.5 \mu \mathrm{g} \mathrm{ml}^{-1}\right)$ and EPG-257 $\left(2.5 \mu \mathrm{g} \mathrm{ml}^{-1}\right)$ and doxorubicin $\left(0.05 \mu \mathrm{g} \mathrm{ml}^{-1}\right)$ for MCF-7 cells (Farmitalia Carlo Erba, Freiburg, Germany). The $24 \mathrm{~h}$ treatment of drug-sensitive cells was performed at the identical drug concentrations.

\section{Sensitivity of cells to doxorubicin and paclitaxel}

Cell proliferation assay (Cell Proliferation Kit I (MTT) Roche, IN, USA,) was used to monitor sensitivity of doxorubicin-resistant cell lines. Protocol was carried out as directed by the manufacturer. Briefly, 5000 cells per well in a microplate were plated, and drug was added after an overnight incubation in increasing grade of
$0.0001 \mathrm{x}-100 \mathrm{x}$ of the clinically administered dose (doxorubicin: $0.02 \mu \mathrm{g} \mathrm{ml}^{-1}$, paclitaxel: $0.025 \mu \mathrm{g} \mathrm{ml}^{-1}$ ) in triplicates. Six days later, MTT (3-[4, 5-dimethylthiazolyl-2]-2, 5-diphenyltetrazolium bromide) was added to each well for $4 \mathrm{~h}$. After this incubation period, the formed purple formazan salt crystals were solubilised and quantified 1 day later with the use a BioTek PowerWave XS Microplate Spectrophotometer.

\section{Autofluorescence of doxorubicin}

A total of 50000 sensitive MCF-7 cells per well were plated in triplicate in a 96-well plate for four different conditions: (1) cells treated by doxorubicin, (2) untreated cells, (3) doxorubicin in L15 medium without cells and (4) L15 medium alone. Doxorubicin treatment $\left(0.2 \mu \mathrm{g} \mathrm{ml}^{-1}\right)$ was carried out on the second day for $1.5 \mathrm{~h}$. MTT staining and reading the results were performed as described above. Differences were assessed by using a $t$-test.

\section{RNA isolation and cDNA synthesis}

RNA was isolated from $1 \times 10^{7}$ cells in logarithmic growth phase using the Qiagen RNeasy Mini Kit following the manufacturer's protocol (Qiagen $\mathrm{GmbH}$, Hilden, Germany). Isolated total RNA was quantified by UV-spectroscopy and quality checked by analysis on a LabChip (BioAnalyzer, Agilent Technologies, Santa Clara, CA, USA). RNA samples were stored at $-80^{\circ} \mathrm{C}$. cDNA was synthesised from $5 \mu \mathrm{g}$ total RNA by firstly annealing to $5 \mathrm{pmol} \mu \mathrm{l}^{-1}$ HPLC purified T7- (dT)24 primer (MWG-Biotech, Ebersberg, Germany) at $70^{\circ} \mathrm{C}$ for $10 \mathrm{~min}$. Second, reverse transcription, second-strand synthesis and cleanup of double-stranded cDNA was performed according to the protocols provided by Affymetrix (http://www.affymetrix.com/index.affx). Synthesis of biotin-labelled cRNA was performed using the BioArray High Yield RNA Transcription kit (Enzo Diagnostics, Farmingdale, NY, USA). cRNA concentration was determined by UV-spectroscopy and the distribution of cRNA fragment size was checked on a LabChip (BioAnalyzer, Agilent Technologies).

\section{Hybridization protocol}

The fragmented cRNA was hybridised to the HG-U133A arrays (Affymetrix, Santa Clara, CA, USA) in a hybridization oven at $45^{\circ} \mathrm{C}$ for $16 \mathrm{~h}$. Subsequent washing and staining of arrays was performed using the GeneChip fluidics station protocol EukGE-WS2. Finally, probe arrays were scanned using the GeneChip System confocal scanner (Hewlett-Packard, Santa Clara, CA, USA). For each cell line triplicates (sensitive, resistance and treated), hybridization was made once, so altogether 12 hybridizations were made. The microarray data can be downloaded from GEO (accession no. GSE3926).

\section{Pre-processing of microarray data}

Quality control analysis was performed according to the suggestions of The Tumor Analysis Best Practices Working Group (Hoffman et al, 2004). Scanned images were inspected for artefacts. All RNA targets included in the analysis exhibited present calls of $>25 \%$ and were not degraded. We have applied RMA (Irizarry et al, 2003) for the normalization of hybridization intensities. The pre-processing was performed using Bioconductor packages in the $\mathrm{R}$ statistical environment. RMA is one of the most common array normalization methods supplying cross-project normalization with good specificity and excellent sensitivity.

\section{Feature selection}

We arranged the complete data set into three classes according to the resistance and treatment properties of the cell lines. We 


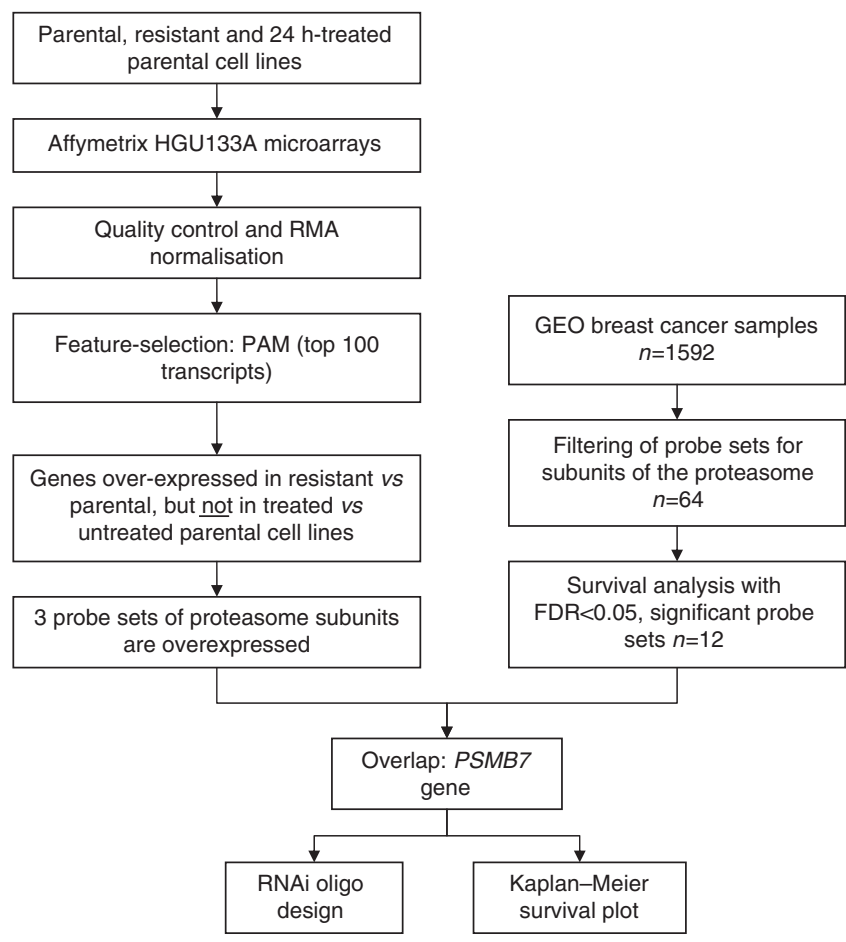

Figure I Overview of the statistical analysis.

compared drug-sensitive parental, doxorubicin/daunorubicintreated parental and resistant cell lines. For identifying discriminating genes, the Prediction Analysis for Mircorarrays (PAM v.1.23) package was used as described earlier (Tibshirani et al, 2002). PAM uses soft thresholding for producing a shrunken centroid, which allows the selection of genes with high discriminative potential. An overview of the applied statistical approach is presented in Figure 1. We decided to pick the top 100 genes from each comparison for the selection of the best discriminatory group of genes. Then genes were identified, which discriminate between parental and treated parental cell lines (reflecting effect of the drug treatment) and resistant and parental cell lines (reflecting genes of resistance).

\section{Additional analyses}

Hierarchical clustering was performed using the Genesis software (Sturn et al, 2002). Before clustering, we performed a second normalization at the gene level to set the average expression of each transcript to 0 to present gene inductions or repressions of identical magnitude as numerically equal. Gene annotations were performed using the Netaffx Analysis Centre (http://www.affymetrix. com/analysis/index.affx).

\section{Immunohistochemistry}

Cells were grown on microscopic slides and fixed in ice-cold methanol-acetone mixture $(1: 1)$. Activity of endogenous peroxidase was blocked by incubation in $1 \% \mathrm{H}_{2} \mathrm{O}_{2}$. Immunohistochemical stainings were carried out in triplicate with primary antibody polyclonal antiserum against PSMB7 (dilution 1:200; GenWay Biotech, Inc., CA, USA). Subsequently, slides were incubated with secondary biotinylated antibodies anti-mouse, rabbit and goat; optimally prediluted from LSAB + , HRP Kit (DakoCytomation, Glostrup, Denmark); followed by optimally prediluted streptavidinbiotinylated peroxidase complex (LSAB,+ HRP, DakoCytomation) and the chromogen NovaRed (Vector Laboratories, Peterborough,
UK) at room temperature. The intensity of antigen expression was measured using the digital imaging system Lucia-G/F (Nikon, Tokyo, Japan). Mean saturation feature was determined in four microscopic fields at 200 -fold magnification. Nucleus staining was performed by DAPI (4',6-diamidino-2-phenylindole).

\section{Oligos for RNAi}

Target of siRNA oligos for PSMB7 were designed using siRNA Target Finder (http://www.ambion.com) and siDESIGN Center (http://www.dharmacon.com) softwares. DNA oligonucleotide templates for three target mRNAs were ordered (Csertex $\mathrm{Kft}$, Budapest, Hungary), then were synthesised by Silencer siRNA Construction Kit (Applied Biosystems, Darmstadt, Germany) using the manufacturer's instruction. Synthesised siRNA duplex concentrations were measured by NanoDrop ND-1000 spectrophotometer (BCM, Houston, TX, USA) then diluted as needed. PCR primers were designed by Primer3 software (http://frodo.wi.mit. edu/) and their binding site was verified by NCBI BLAST (http:// blast.ncbi.nlm.nih.gov/Blast.cgi). Out of three synthesised siRNA oligos, one silenced effectively PSMB7 better than $80 \%$. Figure 3 shows binding location of every synthesised oligos and PCR primers (effective siRNA is framed by continuous line). Effectiveness of siRNA oligos was validated by RT - PCR (Figure 3B).

\section{SiRNA transfection of MCF-7 cell lines}

Transfection was carried out with $5 \mu$ l SiPORT NeoFX Transfection Reagent (Applied Biosystems, Budapest, Hungary) in six-well plates. A total of 230000 cells were plated into each well. The final concentration of siRNA was $10 \mathrm{~nm}$ in $2.5 \mathrm{ml}$ serum and antibioticfree medium. After $24 \mathrm{~h}$ of incubation, medium was washed twice with sterile PBS, then normal growth medium was added. Total RNA was extracted in the 48th h after transfection with Qiagen RNeasy Mini Kit as described earlier, cDNA synthesis and DNA amplification were carried out by OneStep RT-PCR Kit (Qiagen $\mathrm{GmbH}$ ) with gene-specific PCR primers. GAPDH was used as internal control. We used 24 amplification cycles for amplification. Amplification products were separated on $2 \%$ agarose gel stained with ethidium-bromide. The effect of silencing was calculated by Adobe Photoshop CS2 software.

\section{Combination of RNAi and chemotherapy treatment}

To investigate the function of selected gene in chemoresistance, we combined RNAi and drug treatment. PSMB7 overexpressed in resistant cells was silenced in doxorubicin-resistant MCF-7 cell lines (MCF-7-RAdr); $24 \mathrm{~h}$ after transfection, the reaction was stopped by replacing the medium with normal growth medium containing drug in concentration of $0.2 \mu \mathrm{g} \mathrm{ml}^{-1}$. Cells were trypsinised on the 72nd h and counted by CASY DT Cell Counter (Innovatis AG, Reutlingen, Germany). We used negative siRNAtreated (AllStars Negative Control siRNA, Qiagen GmbH) MCF-7RAdr cells, siRNA-untreated MCF-7-RAdr cells and siRNAuntreated MCF-7 cells for controls with their doxorubicin-treated analogue. For a statistical analysis, the number of living cells was counted in each well. Experiments were carried out three times, and each well was measured three times in each experiment. The number of drug-treated cells was normalised to untreated cells in siRNA-treated, negative siRNA-treated and siRNA-untreated wells. The $t$-test was used for analysis of difference between groups. Significance level was set at $P=0.05$.

\section{Validation on clinical samples}

For in silico validation of the genes, a database containing processed GEO microarray samples was established as described earlier (Gyorffy and Schafer, 2009). Dataset includes GSE12276, 
GSE16391, GSE12093, GSE11121, GSE9195, GSE7390, GSE6532, GSE5327, GSE4922, GSE3494, GSE2990, GSE2034 and GSE1456. First, genes were filtered to include only subunits of the proteasome $(n=64)$. Then a survival analysis for each of these probe sets were performed using BRB Arraytools 3.8.0- $\beta \_1$ package (developed by Dr Richard Simon and Amy Peng Lam, available at http://linus.nci.nih.gov/BRB-ArrayTools.html). The false discovery rate (FDR) was set below 0.05. Finally, KaplanMeier plots were drawn to illustrate the effect on survival in these patients.

\section{RESULTS}

\section{Identification of differentially regulated genes}

To identify genes associated with the resistance to doxorubicin/ daunorubicin, we contrasted gene expression profiles of closely related drug-resistant and -sensitive cell lines derived from breast, pancreatic, colon and gastric cancer. For microarray analysis, RNA was prepared from non-treated parental cells, from parental cells treated with doxorubicin for $24 \mathrm{~h}$ and from resistant derivatives cultured continuously in the presence of doxorubicin at a concentration that completely eliminated the sensitive cells. The complete data set comprising raw data and Affymetrix .CEL files is available in the GEO database (http://www.ncbi.nlm.nih.gov/geo/) using the GEO accession number GSE3926. The prediction analysis of microarrays was performed to pick the top 100 genes differentially expressed in each sample set independent of tissue origin. To visualise discriminatory expression changes, we clustered the top genes (see Figure $2 \mathrm{~A}$ and $\mathrm{B}$ ). In these, three probe sets representing proteasome subunits were expressed stronger in doxorubicin-resistant cell lines, but not in doxorubicin-treated parental cells (see arrows in Figure 2).

\section{Autofluorescence of doxorubicin}

Examining the effect of doxorubicin autofluorescence on MTT results, there was no difference between doxorubicin-treated and untreated cells $(P=0.38)$. Fluorescence of doxorubicin supplemented L15 medium differed significantly from doxorubicintreated cells $(P<0.01)$, but did not differ from untreated L15 medium $(P=0.065)$.

\section{Prognostic potential of 64 proteasome subunits}

The normalised gene expression of the GEO-downloaded 1592 samples was filtered to include only the proteasome subunits present on the HG-U133A microarrays. The prognostic potential for all 64 probe sets was computed by dividing the patients into over- and underexpressed group as compared with the median (thus, 531 patients were in each group). The analysis resulted in 12 significant genes below an FDR of 0.05 . Of these, only one was also detected by the microarray analysis (PSMB7), which was further investigated. Immunocytochemistry confirmed the overexpression of PSMB7 as observed on the microarrays (Figure 2C and D).

\section{Survival of cells after gene silencing and treatment with doxorubicin and paclitaxel}

To examine the function of the PSMB7 gene in doxorubicin resistance, we combined gene silencing with drug treatment to assess its effect on cell survival. Viability of cells without doxorubicin treatment was better in both siRNA-untreated and siRNA-treated wells compared with cells with doxorubicin treatment. A specific cytotoxic effect of negative control siRNA was negligible as compared with the effect of gene-specific siRNA.

Data after normalization are presented in Figure 4; $79.8 \pm 13.3 \%$ of resistance cells survived after doxorubicin treatment. Combined with gene silencing, only $31.8 \pm 6.4 \%$ of the MCF-7-RAdr cells survived. The significance between siRNA-treated and siRNAuntreated MCF-7-RAdr cells after doxorubicin treatment was $P>0.001$. After doxorubicin treatment, $48.3 \pm 8.1 \%$ of sensitive cells survived. A total of $73.3 \%$ of negative control siRNA-treated cells survived. After combination of paclitaxel treatment and gene silencing, $22.6 \pm 4 \%$ of the MCF-7-RAdr cells survived compared with siRNA-untreated cells, whereas $43.8 \pm 6 \%$ of sensitive cells survived (data not shown). Relative cell vitality of siRNA-treated and siRNA-untreated MCF-7-RAdr cells after paclitaxel treatment differed significantly $(P=0.03)$.

\section{Biomarker potential of PSMB7 in clinical samples}

To assess the prognostic power of PSMB7 gene in resistance, clinical samples were used to validate the results of cell culture model. We grouped the 1592 breast cancer patients on the basis of the expression of PSMB7 using the Affymetrix HGU133A probe set 200786_at. Of these, 963 out of 1220 patients were ER positive and 187 out of 1156 lymph node positive. The average relapse-free survival was 6.42 years. Unfortunately, detailed treatment history was generally not available. Patients above the median had a significantly shorter survival than patients below the median $(P<0.001)$ (Figure 5).

\section{DISCUSSION}

In our study we examined the function of the proteasome subunit PSMB7 gene in drug resistance in breast cancer cell line and in breast cancer patients. So far, no earlier study has risen up concerning drug resistance neither for PSMB7 gene nor any of proteasome subunits. In a cell culture model with a combination of RNAi and drug treatment, we validated the causative function of this gene in chemoresistance. The examination of 1592 breast cancer patient showed that overexpression of this gene is associated with poor prognostic outcome.

At the preliminary phase of this study, we contrasted the expression profiles of four pairs of different human tumour cell lines of gastric, pancreatic, colon and breast origin, their counterparts resistant to the topoisomerase inhibitors daunorubicin or doxorubicin and the sensitive parental cells after a $24 \mathrm{~h}$ chemotherapy treatment using Affymetrix HG-U133A microarrays. We also performed additional analyses to exclude the influence of doxorubicin autofluorescence (Karukstis et al, 1998) on our results. Finally, we identified the top transcripts associated with doxorubicin/daunorubicin resistance, but not with treatment response. So far, the majority of microarray-based chemoresistance-associated gene sets concentrated on finding genes associated with resistance rather than on the difference between drug response and drug resistance. Surprisingly, we have found genes such as proteasome subunits coding PSMB7 and PSMD13 having function in the mechanism of resistance that earlier have not been described. Of these, only the expression of PSMB7 was able to predict survival in clinical samples and was, therefore, further investigated using RNAi.

The Homo sapiens gene PSMB7 encodes proteasome (also called prosome or macropain) subunit $\beta$-type, 7 . In the Haloarchaeon Haloferax Volcanii proteasomal 20S, components are required for cell growth (Zhou et al, 2008). Proteasome and tRNA modification genes are co-transcribed, revealing that a number of additional enzymes are co-regulated with proteasomes at the transcriptional level in the same species (Gil et al, 2007). Other animal experiments related to proteasome and immunology were made on Japanese pufferfish (Clark et al, 2001) and zebrafish (Michalova et al, 2000). The importance of monitoring proteasomes has emerged in the last couple of years as it has an important function in the degradation of many proteins involved in cell cycle 
A

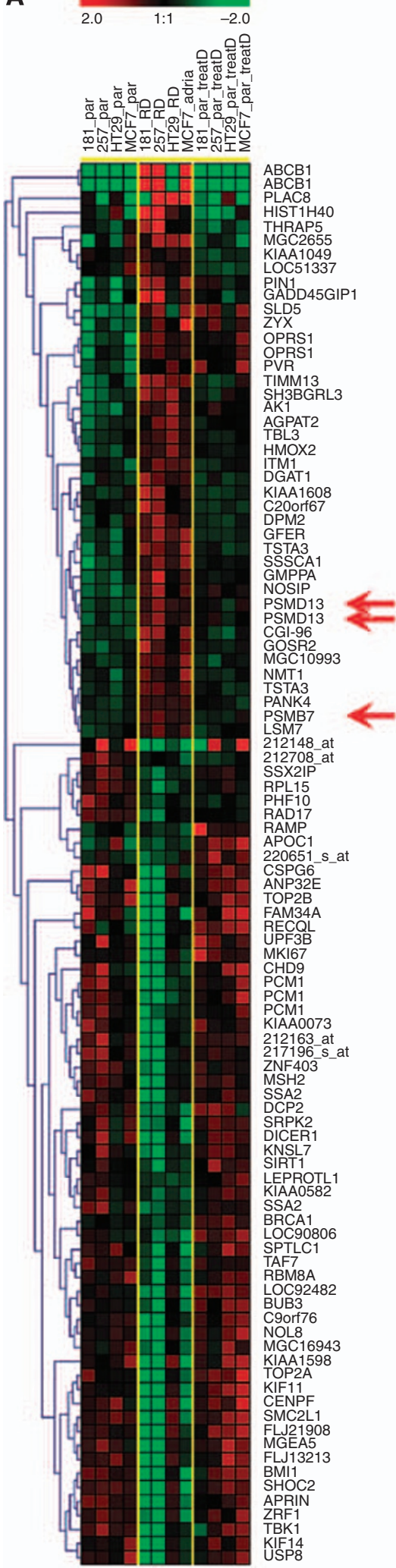

B
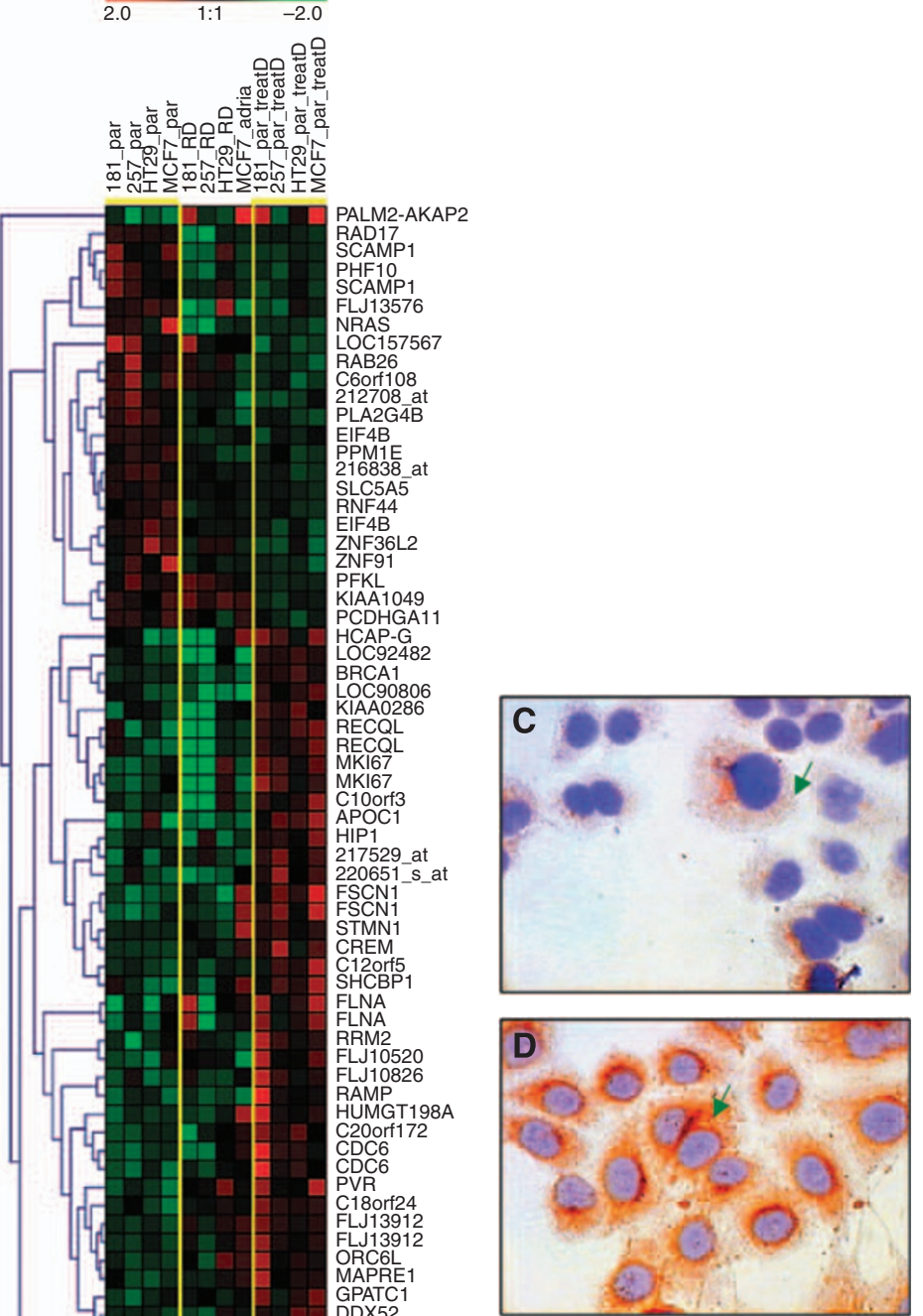

Figure 2 Discriminating transcripts: (A) hierarchical clustering of all three groups (parental, treated parental, resistance cell line) against each other and (B) hierarchical clustering of parental vs treated parental cell lines. Red arrows show appearance of three probe sets measuring proteasome subunits on resistance-associated gene list. Immunohistochemical localization of PSMB7 expression in sensitive (C) and resistant cells (D). Reactions of cytoplasmic localization were obtained for PSMB7 (green arrows). 


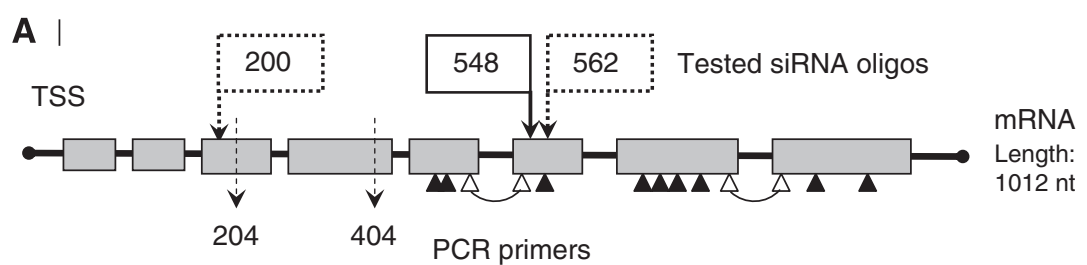

B

\begin{tabular}{|c|c|c|c|c|c|}
\hline \multirow{2}{*}{$\begin{array}{c}\text { Position of } \\
\text { siRNA (nt) }\end{array}$} & \multicolumn{2}{|c|}{ Silencing } & \multicolumn{2}{|c|}{ GAPDH } & \multirow{2}{*}{ Sequence of siRNA (5' to $3^{\prime}$ ) } \\
\cline { 2 - 4 } & Control & $\begin{array}{c}\text { PSMB7 } \\
\text { siRNA }\end{array}$ & Control & $\begin{array}{c}\text { PSMB7 } \\
\text { siRNA }\end{array}$ & \\
\hline 200 & & & & AAGAGCAACTGAAGGGATGGT \\
\hline 548 & & & & AATGGCTGTATTTGAAGATAA \\
\hline 562 & & & & AAGATAAGTTTAGGCCAGACA \\
\hline
\end{tabular}

Figure 3 (A) Schematic view of PSMB7 gene with its eight exons. Splitting positions of tested siRNA oligos are shown ( $\downarrow$ ); the most effective siRNA is marked by continuously bordered box. Binding location of designed PCR primers specific for PSMB7 is shown under the gene by a broken line $(\downarrow)$. Positions of probe sequences of probeset 200786_at on Affymetrix HG-UI33A array are also shown ( $\mathbf{\Delta}$, match probes; $\triangle$, junction probes, overlapping two neighbouring exons). (B) Details of designed siRNA oligos. One out of three siRNA oligos (degrading at 548 nucleotide (nt)) showed effective silencing compared with siRNA-untreated control. GAPDH was used as internal control for both untreated control and siRNA-treated samples. The effect of silencing was $87 \%$ for siRNA binding at position 548 .

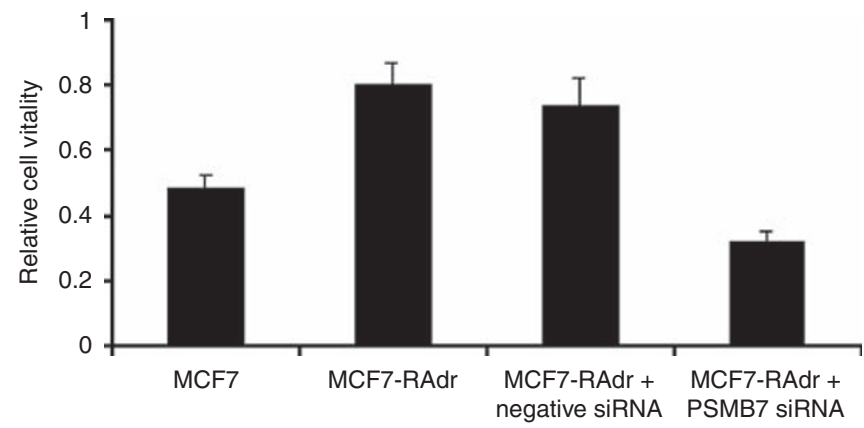

Figure 4 The effect of silencing of PSMB7 on doxorubicin resistance in MCF-7 cells.

regulation, apoptosis and angiogenesis. As these pathways are fundamental for cell survival and proliferation, particularly in cancer cells, the inhibition of proteasome might deliver an attractive potential anticancer therapy. Proteolysis is conducted by $20 \mathrm{~S}$ proteasomes, complexes of 28 subunits arranged as a cylinder in four heteroheptameric rings: $\alpha-1$ to $-7, \beta-1$ to $-7, \beta-1$ to -7 and $\alpha-1$ to -7 . The catalytic subunits are $\beta-1$ (PSMB6), $\beta-2$ (PSMB7) and $\beta-5$ (PSMB5). Three additional subunits, $\beta$-1i (PSMB9), $\beta$-2i (PSMB10) and $\beta$-5i (PSMB8), are induced by $\gamma$-interferon (IFNG) and are preferentially incorporated into proteasomes to make immunoproteasomes. PSMB11, or $\beta-5 \mathrm{t}$, is a catalytic subunit expressed exclusively in cortical thymic epithelial cells (Murata et al, 2007).

The function of one of the catalytic subunits, the PSMB7 gene in cancer is still an undiscovered spot of molecular biology. Its overexpression is described in colorectal carcinomas, in both cytoplasmic and nuclear region (Rho et al, 2008). After adaptation of proteasome inhibitor expression of PSMB5 increased, but other components of proteasome such as PSMB7 did not (Oerlemans et al, 2008). Looking for tissue-specific alteration in proteasome units, researchers treated mice with $3 \mathrm{H}$-1,2-dithiole-3-thione (D3T), which functions as a cancer preventive agent proved both in animal and human studies; $24 \mathrm{~h}$ later, expression of the $20 \mathrm{~S}$ catalytic core subunits PSMB5, PSMB6 and PSMB7 were increased in liver, lung, small intestine and colon of mice (Kwak et al, 2007a).

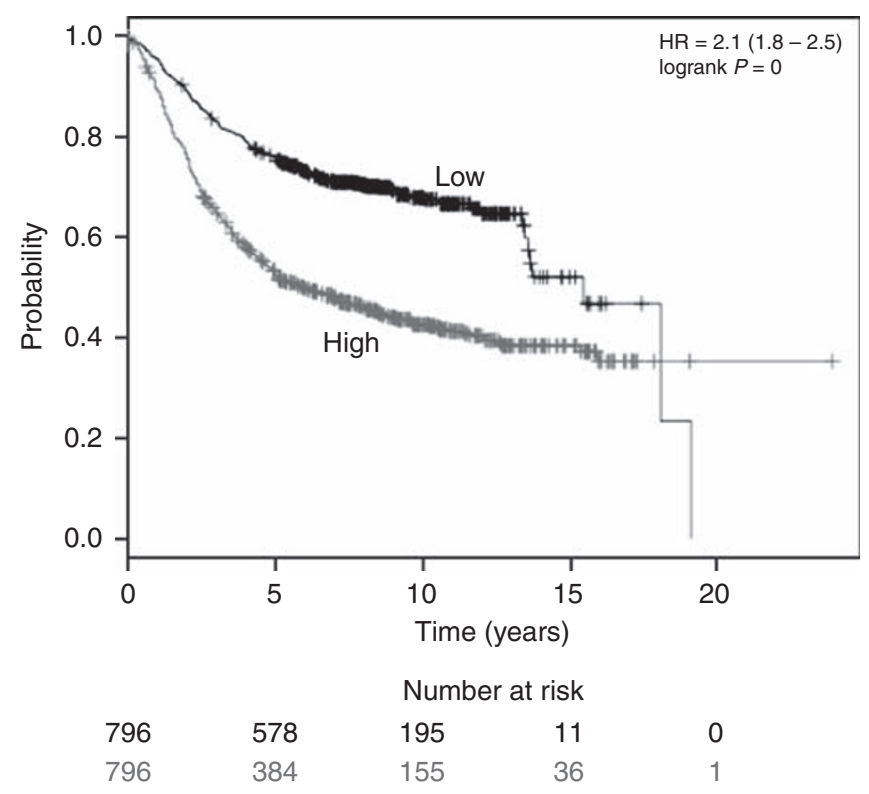

Figure 5 Kaplan-Meier of survival of the 1592 breast cancer patients grouped by the expression of PSMB7 (200786_at probe set) above or below the median.

Elevated expression of proteasome catalytic subunits led to increase in proteasomal peptidase activities in these tissues. Oral administration of D3T also exerted a pharmacodynamic action in some brain regions of these mice and proteasomal peptidase activities were significantly elevated in the cerebral cortexhippocampus. These results indicate that increased proteasome expression by inducers may have a function in protection/ attenuation of protein aggregate-mediated disorders (Kwak et al, 2007b).

After in vitro inspection, we further validated the discriminating function of differential PSMB7 expression in 1592 publicly available microarrays . By dividing the patients as having overor underexpressed PSMB7 as compared with the median, we achieved high significance. However, our approach is limited 
because of inadequate treatment information. A future study for fine tuning of PSMB7 expression with RT - PCR in a large clinical sample collection with detailed clinical follow-up could identify exact cut offs for thresholds, which could validate and enhance its discriminative potential in clinical use.

We might consider the idea to silence overexpressed PSMB7 as part of a chemotherapy. However, despite promising in vitro results, the establishment of effective RNAi conditions in vivo is still complicated. A major impediment to the clinical use of RNAi therapy is the need to deliver these macromolecules to each and every cancer cell to trigger a direct and specific effect. Several studies have shown in vivo efficacy in the delivery of siRNAs using various strategies such as complexing siRNAs with cationic lipids, nanoparticles, polyethyleneimine, cyclodextrin, chitosan and collagen (Nguyen et al, 2008). Xenograft mouse model was also effectively used in several studies (Xiao et al, 2008; Xie et al, 2008; Zhang et al, 2008, 2009; Shi et al, 2009). In human beings, RNAi is already in clinical use in therapy of macula degeneration and respiratory syncytial virus infection, but so far no effective RNAibased inhibition of tumour progression is available.

As it was examined in the last decades, overexpression of individual genes can be associated with resistance against given agents. $A B C B 1$ gene strongly correlates to chemoresistance (Clarke et al 1992; Kamata et al, 2008; Larbcharoensub et al, 2008; Shi et al, 2008), TOP2A is a potential gene for predicting anthracyclin resistance (Molina et al, 2005; Tanner et al, 2006; Harris et al, 2007; Mano et al, 2007). Expression of metallothioneins is linked to tamoxifen resistance (Surowiak et al, 2004), and the gene Tau is a predictor of resistance against neoadjuvant paclitaxel therapy (Rouzier et al, 2005; Andre et al, 2007). The favourable outcome of this study suggests that PSMB7 gene has an important function in predicting both doxorubicin and paclitaxel resistance.

In summary, our findings support the function of the proteasome in the development of chemotherapy resistance. High $P S M B 7$ expression is an unfavourable prognostic marker in breast cancer.

\section{ACKNOWLEDGEMENTS}

BG was supported by a Bolyai fellowship and by the ETT grant 029-01. Research infrastructure used in this study was supported by the 'Fuss a rákkutatásért' Foundation.

\section{REFERENCES}

Adams J, Palombella VJ, Sausville EA, Johnson J, Destree A, Lazarus DD, Maas J, Pien CS, Prakash S, Elliott PJ (1999) Proteasome inhibitors: a novel class of potent and effective antitumor agents. Cancer Res 59: $2615-2622$

Andre F, Hatzis C, Anderson K, Sotiriou C, Mazouni C, Mejia J, Wang B, Hortobagyi GN, Symmans WF, Pusztai L (2007) Microtubule-associated protein-tau is a bifunctional predictor of endocrine sensitivity and chemotherapy resistance in estrogen receptor-positive breast cancer. Clin Cancer Res 13: 2061-2067

Ayers M, Symmans WF, Stec J, Damokosh AI, Clark E, Hess K, Lecocke M, Metivier J, Booser D, Ibrahim N, Valero V, Royce M, Arun B, Whitman G, Ross J, Sneige N, Hortobagyi GN, Pusztai L (2004) Gene expression profiles predict complete pathologic response to neoadjuvant paclitaxel and fluorouracil, doxorubicin, and cyclophosphamide chemotherapy in breast cancer. J Clin Oncol 22: 2284-2293

Ciolli S, Leoni F, Casini C, Breschi C, Santini V, Bosi A (2008) The addition of liposomal doxorubicin to bortezomib, thalidomide and dexamethasone significantly improves clinical outcome of advanced multiple myeloma. Br J Haematol 141: 814-819

Clark MS, Shaw L, Kelly A, Snell P, Elgar G (2001) Characterization of the MHC class I region of the Japanese pufferfish (Fugu rubripes). Immunogenetics 52: $174-185$

Clarke R, Currier S, Kaplan O, Lovelace E, Boulay V, Gottesman MM, Dickson RB (1992) Effect of P-glycoprotein expression on sensitivity to hormones in MCF-7 human breast cancer cells. J Natl Cancer Inst 84: $1506-1512$

Cleator SJ, Powles TJ, Dexter T, Fulford L, Mackay A, Smith IE, Valgeirsson H, Ashworth A, Dowsett M (2006) The effect of the stromal component of breast tumours on prediction of clinical outcome using gene expression microarray analysis. Breast Cancer Res 8: R32

Folgueira MAAK, Carraro DM, Brentani H, Patra DFD, Barbosa EM, Netto MM, Caldeira JRF, Katayama MLH, Soares FA, Oliveira CT, Reis LFL, Kaiano JHL, Camargo LP, Vencio RZN, Snitcovsky IML, Makdissi FBA, Silva PJDE, Goes JCGS, Brentani MM (2005) Gene expression profile associated with response to doxorubicin-based therapy in breast cancer. Clin Cancer Res 11: 7434-7443

Gewirtz DA (1999) A critical evaluation of the mechanisms of action proposed for the antitumor effects of the anthracycline antibiotics adriamycin and daunorubicin. Biochem Pharmacol 57: 727-741

Gianni L, Zambetti M, Clark K, Baker J, Cronin M, Wu J, Mariani G, Rodriguez J, Carcangiu M, Watson D, Valagussa P, Rouzier R, Symmans WF, Ross JS, Hortobagyi GN, Pusztai L, Shak S (2005) Gene expression profiles in paraffin-embedded core biopsy tissue predict response to chemotherapy in women with locally advanced breast cancer. $J$ Clin Oncol 23: $7265-7277$
Gil MA, Sherwood KE, Maupin-Furlow JA (2007) Transcriptional linkage of Haloferax volcanii proteasomal genes with non-proteasomal gene neighbours including RNase P, MOSC domain and SAM-methyltransferase homologues. Microbiology 153: 3009-3022

Gottesman MM, Fojo T, Bates SE (2002) Multidrug resistance in cancer: role of ATP-dependent transporters. Nat Rev Cancer 2: 48-58

Gyorffy B, Serra V, Jurchott K, bdul-Ghani R, Garber M, Stein U, Petersen I, Lage H, Dietel M, Schafer R (2005) Prediction of doxorubicin sensitivity in breast tumors based on gene expression profiles of drug-resistant cell lines correlates with patient survival. Oncogene 24: $7542-7551$

Gyorffy B, Surowiak P, Kiesslich O, Denkert C, Schafer R, Dietel M, Lage H (2006) Gene expression profiling of 30 cancer cell lines predicts resistance towards 11 anticancer drugs at clinically achieved concentrations. Int J Cancer 118: 1699-1712

Gyorffy B, Schafer R (2009) Meta-analysis of gene expression profiles related to relapse-free survival in 1,079 breast cancer patients. Breast Cancer Res Treat 118: 433-441

Harris L, Fritsche H, Mennel R, Norton L, Ravdin P, Taube S, Somerfield MR, Hayes DF, Bast Jr RC (2007) American Society of Clinical Oncology 2007 update of recommendations for the use of tumor markers in breast cancer. J Clin Oncol 25: 5287-5312

Hess KR, Anderson K, Symmans WF, Valero V, Ibrahim N, Mejia JA, Booser D, Theriault RL, Buzdar AU, Dempsey PJ, Rouzier R, Sneige N, Ross JS, Vidaurre T, Gomez HL, Hortobagyi GN, Pusztai L (2006) Pharmacogenomic predictor of sensitivity to preoperative chemotherapy with paclitaxel and fluorouracil, doxorubicin, and cyclophosphamide in breast cancer. J Clin Oncol 24: 4236-4244

Hoffman EP, Awad T, Palma J, Webster T, Hubbell E, Warrington JA, Spirais A, Wright G, Buckley J, Triche T, Davis R, Tibshirani R, Xiao WH, Jones W, Tompkins R, West M (2004) Guidelines-expression profiling-best practices for data generation and interpretation in clinical trials. Nat Rev Genet 5: 229-237

Irizarry RA, Bolstad BM, Collin F, Cope LM, Hobbs B, Speed TP (2003) Summaries of Affymetrix GeneChip probe level data. Nucleic Acids Res 31: e15

Kamata S, Kishimoto T, Kobayashi S, Miyazaki M (2008) Expression and localization of ATP binding cassette $(\mathrm{ABC})$ family of drug transporters in gastric hepatoid adenocarcinomas. Histopathology 52: 747-754

Kane RC, Farrell AT, Sridhara R, Pazdur R (2006) United States Food and Drug Administration approval summary: bortezomib for the treatment of progressive multiple myeloma after one prior therapy. Clin Cancer Res 12: $2955-2960$

Kang HC, Kim IJ, Park JH, Shin Y, Ku JL, Jung MS, Yoo BC, Kim HK, Park JG (2004) Identification of genes with differential expression in acquired 
drug-resistant gastric cancer cells using high-density oligonucleotide microarrays. Clin Cancer Res 10: 272-284

Karukstis KK, Thompson EH, Whiles JA, Rosenfeld RJ (1998) Deciphering the fluorescence signature of daunomycin and doxorubicin. Biophys Chem 73: $249-263$

Kwak MK, Huang B, Chang H, Kim JA, Kensler TW (2007a) Tissue specific increase of the catalytic subunits of the $26 \mathrm{~S}$ proteasome by indirect antioxidant dithiolethione in mice: enhanced activity for degradation of abnormal protein. Life Sci 80: $2411-2420$

Kwak MK, Huang B, Chang H, Kim JA, Kensler TW (2007b) Tissue specific increase of the catalytic subunits of the $26 \mathrm{~S}$ proteasome by indirect antioxidant dithiolethione in mice: enhanced activity for degradation of abnormal protein. Life Sci 80: $2411-2420$

Lage H, Dietel M (2002) Multiple mechanisms confer different drugresistant phenotypes in pancreatic carcinoma cells. Cancer Res Clin Oncol 128: $349-357$

Larbcharoensub N, Leopairat J, Sirachainan E, Narkwong L, Bhongmakapat $\mathrm{T}$, Rasmeepaisarn K, Janvilisri T (2008) Association between multidrug resistance-associated protein 1 and poor prognosis in patients with nasopharyngeal carcinoma treated with radiotherapy and concurrent chemotherapy. Hum Pathol 39: 837-845

Ludwig H, Khayat D, Giaccone G, Facon T (2005) Proteasome inhibition and its clinical prospects in the treatment of hematologic and solid malignancies. Cancer 104: $1794-1807$

Mano MS, Rosa DD, De AE, Ismael GF, Durbecq V (2007) The 17q12-q21 amplicon: Her2 and topoisomerase-IIalpha and their importance to the biology of solid tumours. Cancer Treat Rev 33: 64-77

Martin M, Villar A, Sole-Calvo A, Gonzalez R, Massuti B, Lizon J, Camps C, Carrato A, Casado A, Candel MT, Albanell J, Aranda J, Munarriz B, Campbell J, Diaz-Rubio E (2003) Doxorubicin in combination with fluorouracil and cyclophosphamide (i.v. FAC regimen, day 1 , 21) versus methotrexate in combination with fluorouracil and cyclophosphamide (i.v. CMF regimen, day 1,21) as adjuvant chemotherapy for operable breast cancer: a study by the GEICAM group. Ann Oncol 14: $833-842$

Michalova V, Murray BW, Sultmann H, Klein J (2000) A contig map of the Mhc class I genomic region in the zebrafish reveals ancient synteny. J Immunol 164: 5296-5305

Molina R, Barak V, van DA, Duffy MJ, Einarsson R, Gion M, Goike H, Lamerz R, Nap M, Soletormos G, Stieber P (2005) Tumor markers in breast cancer-European Group on Tumor Markers recommendations. Tumour Biol 26: $281-293$

Montagut C, Rovira A, Mellado B, Gascon P, Ross JS, Albanell J (2005) Preclinical and clinical development of the proteasome inhibitor bortezomib in cancer treatment. Drugs Today (Barc) 41: 299-315

Montagut C, Rovira A, Albanell J (2006) The proteasome: a novel target for anticancer therapy. Clin Transl Oncol 8: 313-317

Murata S, Sasaki K, Kishimoto T, Niwa S, Hayashi H, Takahama Y, Tanaka K (2007) Regulation of CD8+ T cell development by thymus-specific proteasomes. Science 316: 1349-1353

Nguyen T, Menocal EM, Harborth J, Fruehauf JH (2008) RNAi therapeutics: an update on delivery. Curr Opin Mol Ther 10: 158-167

Oerlemans R, Franke NE, Assaraf YG, Cloos J, van ZI, Berkers CR, Scheffer GL, Debipersad K, Vojtekova K, Lemos C, van der Heijden JW, Ylstra B, Peters GJ, Kaspers GL, Dijkmans BA, Scheper RJ, Jansen G (2008) Molecular basis of bortezomib resistance: proteasome subunit beta5 (PSMB5) gene mutation and overexpression of PSMB5 protein. Blood 112: $2489-2499$
Rho JH, Qin S, Wang JY, Roehrl MH (2008) Proteomic expression analysis of surgical human colorectal cancer tissues: up-regulation of PSB7, PRDX1, and SRP9 and hypoxic adaptation in cancer. J Proteome Res 7: $2959-2972$

Rouzier R, Rajan R, Wagner P, Hess KR, Gold DL, Stec J, Ayers M, Ross JS, Zhang P, Buchholz TA, Kuerer H, Green M, Arun B, Hortobagyi GN, Symmans WF, Pusztai L (2005) Microtubule-associated protein tau: a marker of paclitaxel sensitivity in breast cancer. Proc Natl Acad Sci USA 102: $8315-8320$

Sabourin M, Osheroff N (2000) Sensitivity of human type II topoisomerases to DNA damage: stimulation of enzyme-mediated DNA cleavage by abasic, oxidized and alkylated lesions. Nucleic Acids Res 28: 1947-1954

Schewe DM, guirre-Ghiso JA (2009) Inhibition of eIF2alpha dephosphorylation maximizes bortezomib efficiency and eliminates quiescent multiple myeloma cells surviving proteasome inhibitor therapy. Cancer Res 69: $1545-1552$

Shi H, Lu D, Shu Y, Shi W, Lu S, Wang K (2008) Expression of multidrugresistance-related proteins P-glycoprotein, glutathione-S-transferases, topoisomerase-II and lung resistance protein in primary gastric cardiac adenocarcinoma. Cancer Invest 26: $344-351$

Shi XH, Liang ZY, Ren XY, Liu TH (2009) Combined silencing of K-ras and Akt2 oncogenes achieves synergistic effects in inhibiting pancreatic cancer cell growth in vitro and in vivo. Cancer Gene Ther 16: 227-236

Sterz J, von MI, Hahne JC, Lamottke B, Rademacher J, Heider U, Terpos E, Sezer O (2008) The potential of proteasome inhibitors in cancer therapy. Expert Opin Investig Drugs 17: 879-895

Sturn A, Quackenbush J, Trajanoski Z (2002) Genesis: cluster analysis of microarray data. Bioinformatics 18: 207-208

Surowiak P, Paluchowski P, Dziegiel P, Wysocka T, Wojnar A, Spaczynski M, Zabel M (2004) Lack of relationship between metallothionein (MT) expression and proliferation exponents in cells of primary ductal breast cancer of G2 grade of differentiation. Med Sci Monit 10: BR300-BR305

Tanner M, Isola J, Wiklund T, Erikstein B, Kellokumpu-Lehtinen P, Malmstrom P, Wilking N, Nilsson J, Bergh J (2006) Topoisomerase IIalpha gene amplification predicts favorable treatment response to tailored and dose-escalated anthracycline-based adjuvant chemotherapy in HER-2/neu-amplified breast cancer: Scandinavian Breast Group Trial 9401. J Clin Oncol 24: 2428-2436

Tibshirani R, Hastie T, Narasimhan B, Chu G (2002) Diagnosis of multiple cancer types by shrunken centroids of gene expression. Proc Natl Acad Sci USA 99: 6567-6572

Xiao $\mathrm{H}, \mathrm{Wu}$ Z, Shen $\mathrm{H}$, Luo AL, Yang YF, Li XB, Zhu DY (2008) In vivo reversal of P-glycoprotein-mediated multidrug resistance by efficient delivery of stealth RNAi. Basic Clin Pharmacol Toxicol 103: 342-348

Xie SM, Fang WY, Liu Z, Wang SX, Li X, Liu TF, Xie WB, Yao KT (2008) Lentivirus-mediated RNAi silencing targeting $\mathrm{ABCC} 2$ increasing the sensitivity of a human nasopharyngeal carcinoma cell line against cisplatin. J Transl Med 6: 55

Zhang W, Chen Y, Wei H, Zheng C, Sun R, Zhang J, Tian Z (2008) Antiapoptotic activity of autocrine interleukin-22 and therapeutic effects of interleukin-22-small interfering RNA on human lung cancer xenografts. Clin Cancer Res 14: 6432-6439

Zhang X, Ge YL, Tian RH (2009) The knockdown of c-myc expression by RNAi inhibits cell proliferation in human colon cancer HT-29 cells in vitro and in vivo. Cell Mol Biol Lett 14: 305-318

Zhou G, Kowalczyk D, Humbard MA, Rohatgi S, Maupin-Furlow JA (2008) Proteasomal components required for cell growth and stress responses in the haloarchaeon Haloferax volcanii. J Bacteriol 190: 8096-8105 